Article

\title{
A Prospective Study on MBBS Student About Different Visual Aids
}

\author{
Choudhary $\mathbf{R}^{1}$, Dullo $\mathrm{P}^{2}$, Tandon RV ${ }^{3}$, Gupta $\mathrm{U}^{4}$
}

\begin{abstract}
Background: To enhance successful communication medical teachers are increasingly using different visual aids. Objective: To determine medical students perception of different visual aids like black board (BB), over head projector transparencies (OHPT) and, LCD and to generate recommendations for their optimal use. Methods: A questionnaire based study was carried out among first year MBBS students of Government Medical College, Kota, India. The survey was undertaken among 84 Medical students of first year MBBS of batch 2008 after exposing them to different visual aids like BB, OHPT and LCD in Physiology lectures. A few lectures were absolutely on BB, and some were on OHPT and on LCD. Few classes were taken with mixed visual aids. Students were exposed for such visual aids for one year and then they were requested to complete a questionnaire. Data were statistically analyzed by One Sample Chi-square test. Results: 55 (65.48\%) students rated chalk \& black board as best visual aids in understanding the topic better as compared to OHPT and LCD ( $\mathrm{P}<0.01) .47$ (55.95\%) students have good learning experience with black board teaching and it is best mode to note down important points. 56 (66.66\%) students favored LCD as more interesting and interactive visual aids $(\mathrm{P}<0.01)$. It also complete the lecture faster which was advantageous for 69(82.17\%) students. 77 (91.66\%) students wanted mixing of different visual aids $(\mathrm{P}<0.01)$. Mostly $(75 \%)$ do not find any difficulty in switching from one mode to another. No significant gender difference was observed. Conclusion: To improve students learning medical teachers should match the lectures with preferred visual aids. It will maintain interest and enthusiasm among pupil.
\end{abstract}

Key Words: Black board, Teaching, Overhead projector, LCD projector.

J Bangladesh Soc Physiol. 2009 Dec;4(2): 58-63 For author affiliations, see end of text.

http//www.banglajol.info/index.php/JBSP

\section{Introduction}

$\mathbf{T}$ To enhance successful communication, medical teachers must have subject knowledge and knowledge of the

learner and his / her characteristic ${ }^{1}$. Most faculty members have detailed content knowledge as a result of reading and studying avidly within their academic disciplines. However, obtaining knowledge of the learner and heir preference is a

J Bangladesh Soc Physiol. 2009 Dec;4(2): 58-63 vastly under utilized approach to improve classroom instructions.

Generally students prefer to take new information in form of sensory modality. Three major sensory modalities one visual (V), aural (A) and kinesthetic (K) means writing ${ }^{2}$.

Traditional lectures have an important place in the medical curriculum. In order to help students 
master the increasing advance of medical knowledge, it is necessary to use different visual aids, which can enhance successful communication $^{3,4}$.

To determine medical student's perception about blackboard, over head projector transparencies (OHPT) and LCD as visual aid and to generate recommendation for their optimal use, a questionnaire based study was carried out among first year MBBS students of Government Medical College, Kota, India.

\section{Methods}

A survey was undertaken among 84 medical students of first year MBBS of 2008 batch after exposing them to different visual aids like, black board (BB), over head projector transparencies (OHPT) and LCD in Physiology lectures. A few lectures were absolutely on BB, and a few were on OHPT and LCD. Few classes were taken with mixed visual aids. Students were exposed for such visual aids for 1 (one) year and they were requested to complete a questionnaire. The exercise was voluntary; consent was taken to be implied in the instance that filled questionnaires were returned. Separate written consent was thus not requested. In instances where the questionnaire was not returned or was returned unfilled; the student was considered a non-respondent.

Since a revalidated questionnaire could not be found in the literature, so that we have designed one suited as our needs. The questions asked were: (1) Which mode you think is best to note down important point. (2) Which is most advantageous mode to cover most subject matter per lecture? (3) Which mode of visual aid completes the system fastest? (4) Most sleeping inducing mode of teaching. (5) Best mode which helps to recall the tough point. (6) Which mode develops the ability to understand the topic better? (7) With which mode you have good learning experience. (8) Which mode is more interesting and interactive? (a) Should different modes be mixed with each other, if yes (b) then in which manner would you like. (9) Should seminars be conducted with different modes? (10) Do you find any difficulty in switching from one mode of teaching to other within short duration? (11) Should photocopy material be provided after lecture?

The questionnaire was anonymous and no reference to the identity of the respondent by name or signature. The tenets of the Declaration of Helsinki were followed in all cases. The primary outcome measures were the frequency of first choices awarded to the media in response to these questions. The result's were statistically analyzed by One Sample Chi-square test, at 5\% level of significance taking expected chance as equal for each aspect. For comparison between male and female student's Chi-square analysis was carried out.

\section{Results}

100 students attended the class and 84 responded (27 females \& 57 males) to the openended questionnaire (Table - I).

55 (65.48 \%) students rated chalk and black board as best in understanding the topic better $(\mathrm{p}<0.01)$ as compared to OHPT and LCD and they 47 (55.95\%) also have good learning experience with BB teaching $(\mathrm{p}<0.01)$. Compared to other visual aids $\mathrm{BB}$ teaching is best to note down important points ( $<<0.01)$.

LCD was considered as more interesting and interactive by 56 (66.66\%) students ( $\mathrm{p}<0.01)$. LCD visual aid was best to recall the tough points $(p<0.01)$. With LCD lecture is completed fastly and it was advantageous for 69 (82.17\%) students. This mode also covers the most of the subject matter per lecture ( $\mathrm{p}<0.01) .16$ (19.05\%) students feel this as disadvantage.

J Bangladesh Soc Physiol. 2009 Dec;4(2): 58-63 
Study about Different Visual Aids

Article

Table I: Viewing medical student's responses on questions ( $\mathrm{n}=84)$

Question Whole class (84) $\quad$ Boys (57)

(01) Which mode you think is best to note down important points

$\begin{array}{lccc}\text { A) BB } & * 56(65.8 \%) & * 35(60.3 \%) & * 21(77.8 \%) \\ \text { B) OHPT } & 04(4.76 \%) & 03(5.17 \%) & 01(3.7 \%) \\ \text { C)LCD } & 24(28.57 \%) & 19(32.75 \%) & 05(18.51 \%) \\ \text { P value } & <0.001 & <0.0001 & <0.0001\end{array}$

(02) Which is most advantageous mode to cover most subject matter per lecture
A) BB
$20(23.8 \%)$
$11(19.3 \%)$
$09(33.3 \%)$
B) OHPT
$08(9.52 \%)$
$05(8.77 \%)$
$03(11.1 \%)$
C)LCD *56(66.7\%)
*41(71.9\%)
*15(55.6\%)
P value
$<0.0001$
$<0.0001$
$<0.0001$
Advantage $\quad 68(80.95 \%)$
$45(78.95 \%)$
$23(85.18 \%)$
Disadvantage
$16(19.05 \%)$
$12(24.56 \%)$
04(14.81\%)

(03) Which method of lecture completes the system faster
A) BB
07(8.33\%)
$06(10.5 \%)$
01(3.7\%)
B) OHPT
08(9.52\%)
$07(12.28 \%)$
$01(3.7 \%)$
C) LCD
*69 (82.1\%)
*44(77.2\%)
*25(92.6\%)
$P$ value
$<0.0001$
$<0.0001$
$<0.0001$
Advantage
$57(67.9 \%)$
$40(70.17 \%)$
$17(62.96 \%)$
Disadvantage
$27(32.14 \%)$
$17(29.82 \%)$
$10(37.04 \%)$

(04) Most sleep inducing mode of teaching
A) BB 17(20.24\%)
$13(22.8 \%)$
04(14.8\%)
B) OHPT
*43(51.2\%)
*26(45.6\%)
*17(62.9\%)
C) LCD
$24(28.6 \%)$
$18(31.58 \%)$
06(22.22\%)
$P$ value
$<0.0001$
0.3261
0.0043

(05) Best mode which helps to recall the tough points
A) BB 37(44.05\%)
B) OHPT
06(7.14\%)
*27(47.4\%)
10(37.04\%)
$00(0 \%)$
C)LCD
$* 41(48.8 \%)$
06(10.53\%)
*17(62.9\%)
P value
$<0.0001$
$24(42.11 \%)$
$<0.0003$

(06) Which mode develops the ability to understand the topic better
A) $\mathrm{BB}$
*55(65.5\%)
*36(63.2\%)
*19(70.4\%)
B) OHPT
05(5.95\%)
03(15.26\%)
$02(7.41 \%)$
C) LCD
$24(28.57 \%)$
$18(31.58 \%)$
06(22.22\%)
$P$ value
$<0.0001$
$<0.0001$
$=0.0002$

(07) With which mode you have good learning experience
A) BB
$* 47(55.9 \%)$
*32(56.2\%)
*15(55.5\%)
B) OHPT
07(8.33\%)
05(8.77\%)
02(7.41\%)
C) LCD 30(35.71\%)
20(35.09\%)
10(37.04\%)
P value $<0.0001<0.0001=0.0084$

J Bangladesh Soc Physiol. 2009 Dec;4(2): 58-63 
Table to be continued

\begin{tabular}{cccc}
\hline Question & Whole class (84) & Boys (57) & Girls (27) \\
\hline (08) Which mode is more interesting and interactive & & \\
A) BB & $20(23.81 \%)$ & $12(21.05 \%)$ & $08(29.63 \%)$ \\
B) OHPT & $08(9.52 \%)$ & $07(12.28 \%)$ & $01(3.7 \%)$ \\
C) LCD & $* 56(66.6 \%)$ & $* 38(66.6 \%)$ & $* 18(66.6 \%)$ \\
P value & $<0.0001$ & $<0.0001$ & $=0.0003$ \\
(09a) Should different modes be mixed with each other & & \\
Yes & $* 77(91.6 \%)$ & $* 52(91.2 \%)$ & $* 25(92.5 \%)$ \\
No & $07(8.33 \%)$ & $05(8.77 \%)$ & $02(7.41 \%)$ \\
P value & $<0.0001$ & $<0.0001$ & $<0.0001$ \\
A) BBT + OHPT & $07(8.33 \%)$ & & $01(3.7 \%)$ \\
B) BBT + LCD & $63(75 \%)$ & $06(10.53 \%)$ & $22(81.48 \%)$ \\
C) All combined & $14(16.66 \%)$ & $41(71.93 \%)$ & $04(14.81 \%)$ \\
(09b) Different integrated modes are & $10(17.54 \%)$ & \\
Yes & $* 76(90.5 \%)$ & & $* 24(88.9 \%)$ \\
No & $08(9.52 \%)$ & $* 52(91.5 \%)$ & $03(11.11 \%)$ \\
P value & $<0.0001$ & $05(8.77 \%)$ & $<0.0001$
\end{tabular}

(11) Do you find any difficulty in switching from one mode of teaching to other within short duration

$\begin{array}{lccc}\text { Yes } & 30(35.71 \%) & 26(45.61 \%) & 04(14.81 \%) \\ \text { No } & * 54(64.3 \%) & * 31(54.4 \%) & * 23(85.2 \%) \\ P \text { value } & <0.0001 & <0.0001 & <0.0001\end{array}$

(12) Should photocopy material be provided after teaching

\begin{tabular}{lccc} 
Yes & $* 83(98.8 \%)$ & $* 57(100 \%)$ & $* 26(96.3 \%)$ \\
No & $01(1.19 \%)$ & $00(0 \%)$ & $01(3.7 \%)$ \\
P value & $<0.0001$ & $<0.0001$ & $<0.0001$ \\
\hline
\end{tabular}

$\mathrm{P}>0.05$ is found on comparing Boy's with Girl's response by Chi-square analysis. * On comparing with other options in a question significant difference was found $(\mathrm{p}<0.01)$ [one sample Chi-square test]

Finally 77 (91.66\%) students wanted mixing of different visual aids $(\mathrm{p}<0.01)$ and it is mostly 63 (75\%) favored is BB with LCD aid ( $\mathrm{p}<0.01)$.

154 (64.29\%) students do not find it difficulty in switching from one mode to other with in short duration $(\mathrm{p}<0.01)$.

Even seminars are favored along with different teaching aids 76 (90.48\%) students. No significant gender difference were observed among medical students. For both male and female students, all the responses were rated same as whole class responses.

61
OHPT was considered as most sleep-inducing mode of teaching by 43 (51.20\%) students, $(p<0.01)$. No significant gender differences were observed in results of this study.

\section{Discussion}

Students expect to learn the information being presented so that they can repeat it later on. The lecture itself does not teach the students to analyze; it merely illustrates the process. How much the students learn from the model will

J Bangladesh Soc Physiol. 2009 Dec;4(2): 58-63 
depend both on the clarity with which instructor highlight's the process and on the sophistication level of the listeners.

Black board is most popular type of visual aid as it has easy access and relatively simple to use. It needs no specific equipment except for chalk and black board which is easily affordable.

In this study most of the student's favors' BB as a media with best understanding of topic and with good learning experience. Lecture on Black board allows the students to follow the hands of the teacher and copy the diagrams and conceptualize the information. Structures and procedures that are linked through visualization are more likely to be retained in the long-term memory ${ }^{5}$.

Students in majority feel that both visual aids LCD \& BB should be mixed in teaching. Power point presentation should be used preferably, only for illustration of points not possible with black board and for highlighting important points, special situations where large number of facts are to be given and for summarizations. Technology used simply for the sake of technology may be flashy, but it is most likely pedagogically less useful, use this technology to incorporate active learning, student centered learning in to your lecture ${ }^{6}$.

The students review showed that they are able to interact more with teachers during a chalk and black board lecture, which covers less subject matter per lecture than the other two visual aids.

In there experience LCD allows the material to be presented point wise, which is an advantage. However, this results in too much subject matter being covered per lecture. It impacts recall of topic adversely.

55.95\% students accept black board visual aid as a good learning experience and results were significant. 98.8\% students want photocopy material of teachers lecture.

J Bangladesh Soc Physiol. 2009 Dec;4(2): 58-63
Only $64.29 \%$ students find no difficulty to switch from one mode to another during one hour of teaching schedule.

This study shows that subjectively, in the student's perception, technology does not necessarily make lectures more engaging.

Had a previously validated questionnaire been available it could have been added to the strength of study. To enhance response rate we used an anonymous questionnaire, but that made it difficult to verify the accuracy of responses. Thirdly the study assessed students subjective opinions it did not objectively measure the impact of different visual aids on learning process. An objective assessment of the difference between three visual aids may not elicit similar results ${ }^{7}$. Nevertheless the results are valid. The student's review of this study shows that medical teachers must relearn the optimal use of the audiovisual aids. They must familiarize themselves not only with the topic, but also with visual aids they plan to use. Instructions on the best use of teaching learning media are available in the literature ${ }^{8,9}$. In common with other teaching institutions worldwide, the faculty of this institution use individualized teaching methods and visual aids ${ }^{10}$. The student's responses probably reflect a global phenomenon with wide ranging implications.

\section{Conclusion}

Lecturing using different visual teaching aids is common phenomena. In practice there are many varieties of approaches within each method; within each method there is potential for both competent and in-competent teaching. Emphasize on student learning rather than on quality of presentation. Use LCD to augment rather than to deliver your lecture. Student need to be an appropriate mixing of LCD with black board teaching in classroom for optimal benefit to the students. 


\section{Author affiliations}

1. *Raghuveer Choudhary, Assistant Professor, Department of Physiology, Government Medical College, Kota, India. Email: drraghu74@yahoo.com, 4f/54 New Power House Road, Jodhpur, Rajasthan, Pin code 342001, India, Phone-919829216643

2. Puja Dullo, Assistant Professor, Department of Physiology, Government Medical College, Kota, India

3. RV Tandon, Associate Professor, Department of Physiology, Government Medical College, Kota, India

4. Usha Gupta, Professor and Head Department of Physiology, Government Medical College, Kota, India

* For correspondence

\section{References}

1. Gudmundsdottir S, Shulman L. Pedagogical content knowledge in social studies. Scand J Edu Res; 1987; 31:59-70.

2. Fleming ND. I'm different: not dumb: modes of presentation (VARK) in the tertiary classroom. In: Research and Development in Higher Education, edited by Zelmer A. Canberra, Australia: Proceedings of the 1995 Annual Conference of the Higher Education and Research Development Society of Australia, 1995.p-303-318.
3. Brill JM \& Galloway C. Perils and Promises: University Instructors Integration of Technology in Classroom-Based Practices. British Journal of Educational Technology, 2007; 38:95-105.

4. Leopresti ME. How to use Audiovisual aids a 25 year update. Medical Teacher, 2004; 26:20-22.

5. Brown G, Manogue M. AMEE Medical Education Guide No-22: Refreshing Lecturing: a guide for lecturer. Medical Teacher,2001;23(3):231-244.

6. Denbest M. Power Point, Technology and the web: More than just an Over Head Projector for the New Century. The History Teacher, 2003; 36:4.

7. Ten Cate O. What happens to the student? The neglected variable in educational outcome research. Adv Health Sci Educ Theory Practice,2001; 6: 81-8.

8. Harikrishnan KM. Audiovisual aids: guidelines for the use of overhead projector. J Assoc Physicians India, 1996; 44:395-6.

9. Simmonds D. Standards for medical graphics' Audiov Media Med, 1993; 16:56-61.

10. Pinsky LE, Monson D, Irby DM. How excellent teachers are made: reflecting on success to improve teaching. Adv Health Sci Edu Theory Practice, 1998; 3: 205-215. 